\title{
Pemeriksaan Kadar Asam Urat Dan Konseling Di Kelurahan Bercak Wonosamudro Boyolali Jawa Tengah
}

\author{
Joko Tri Atmojo ${ }^{1 *}$, Ndaru Syukma Putra ${ }^{2}$, Ahmad Syauqi Mubarok ${ }_{5}^{3}$, Asruria Sani \\ Fajriah $^{4}$, Aris Widiyanto \\ ${ }^{1,5}$ STIKES Mamba’ul 'Ulum Surakarta \\ ${ }^{2,3,4}$ Institut Ilmu Kesehatan Strada Indonesia \\ *Email: jokotriatmojo1@gmail.com
}

\begin{abstract}
Background: Uric acid is a disease that arises from excessive blood uric acid levels, which causes excessive blood uric acid levels, which is the production of more uric acid in the body from its disposal. There are several causes of gout, including changes in diet, consumption of drugs, and alcohol consumption. The purpose of implementing this community service activity is to provide education to the community in Bercak Village and to check uric acid levels. Methods: Based on the team's observations on several residents in Bercak Village, it was found that most residents did not have sufficient knowledge about gout and did not carry out routine health checks. In order to increase awareness and understanding of residents about health care efforts, especially preventing gout, the team coordinated with the urban village to carry out community service activities in Bercak Village, Wonosamudro, Boyolali. Results: The target in implementing this program is all residents in the Bercak Village, Wonosamudro, Boyolali. Community service activities were carried out on March 13, 2021, attended by the village head and also village officials and babinsa. Conclusion: After carrying out the activity, it is hoped that the community can follow up on the results of the examination and improve the behavior of efforts to prevent gout.
\end{abstract}

Keywords: examination, uric acid levels, counseling;

\section{PENDAHULUAN}

Asam urat merupakan penyakit kareana adanya kumpulan produk metabolisme purin dalam tubuh (Barsoum \& El-Khatib, 2017). Penyebab utama gout sendiri yaitu gangguan metabolisme hiperurisemia yang didefinisikan sebagai peninggian kadar asam urat lebih dari 7,0 ml/dl dan 6,0 mg/dl.(Widiyanto et al. 2020). Artritis gout (asam urat) biasanya memiliki gejala yaitu timbulnya rasa nyeri pada bagian sendi tubuh, peradangan pada sendi yang tertekan, dan kemerahan pada daerah yang telah terjadi asam urat, kekakuan serta pembengkakan pada sendi yang tertekan (Mahendra \& Arum, 2021). Hiperurisemia merupakan kondisi meningkatnya kadar asam urat dalam darah. Asam urat merupakan produk akhir dari metabolisme purin (Rosdiana et al. 2018).

Asam urat dapat disebabkan oleh dua faktor utama yaitu tingginya produksi kadar purin dalam tubuh akibat sintesis purin yang berlebihan dan penurunan ekskresi asam urat dalam tubulus distal ginjal (Yunita, Fitriana \& Gunawan, 2018). Asam urat adalah senyawa sukar larut dalam air yang merupakan hasil akhir metabolisme purin (Ndede et al, 2019). Dampak tingginya gout akan menimbulkan berbagai penyakit antara lain: rematik,gout, trofi otot, gangguan fungsi ginjal dan batu urat dalam ginjal, infark miokard, diabetes melitus serta kematian dini (Care, 2019).

Penanganan yang dapat dilakukan untuk mencegah terjadinya peningkatan kadar asam urat dalam darah, antara lain pengaturan diet, menghindari makanan tinggi purin, konsumsi vitamin dan mineral yang cukup, olahraga rutin, berhenti merokok, pengendalian stres dan dapat diberikan obatobatan untuk terapi farmakologi, pengobatan lain yang dapat digunakan untuk mengatasi peningkatan kadar asam urat 
yaitu dengan pengobatan herbal (Pasalic, Marinkovic, and Feher-Turkovic 2012). Beberapa contoh makanan yang dapat menrunkan kadar asam urat yaitu daun salam karena mengandung flavonoid yang mampu menurunkan kadar asam urat (Aprillia, Rahmawatie, and Noorratri 2019), Jus sirsak karena dapat menghambat proses pembentukan asam urat dalam tubuh (Sani, Jurnal, 2019).

Fakta yang ditemui di masyarakat saat ini menunjukkan bahwa masyarakat lebih banyak mengkonsumsi obat obatan sebagai terapi penyembuhan gout, sedangkan terapi nonfarmakologi juga efektif digunakan untuk menurunkan kadar asam urat dalam darah (Harrold et al. 2012). Pemahaman masyarakat yakni mitos bahwa ngilu sendi yang dirasakan merupakan gejala dari penyakit asam urat. Beberapa pendapat menyatakan bahwa aktivitas yang berat dapat memperberat penyakit gout ataupenyakit asam urat yang ditandai dengan peningkatan kadar asam uratdalam darah (Syarifuddin et al. 2019).

Dengan kondisi tersebut maka masyarakat perlu diberikan pemahaman yang benar bahwa tidak semua keluhan dari nyeri sendi disebabkan oleh asam urat. Selain itu, masyarakat beranggapan bahwa solusi untuk terhindar dari asam urat adalah dengan tidak mengkonsumsi sayuran hijau dan kacang-kacangan (Fitriani et al. 2021). Hal tersebut tentu salah karena tidak terbukti secara ilmiah.

Diperlukan suatu upaya untuk memberikan pemahaman yang benar mengenai persepsi masyarakat yang tidak tepat dengan memberikan pendidikan kesehatan atau konseling serta untuk memberikan kepastian kepada masyarakat apakah kadar asam uratnya normal atau tidak melalui pemeriksaan kadar asam urat (JAK Sari, 2019). Pengabdian masyarakat dilaksanakan di Kelurahan Bercak, Wonosamudro, Boyolali karena berdasarkan hasil observasi di daerah tersebut banyak masyarakat yang kurang memahami mengenai asam urat dan kurangnya kesadaran masyarakat untuk memeriksakan kesehatannya secara rutin (Muhaimin et al. n.d. 2020).

\section{TINJAUAN PUSTAKA}

Konseling (counseling) disebut juga penyuluhan adalah suatu bentuk bantuan. Konseling merupakan suatu proses pelayanan yang melibatkan kemampuan profesional pada pemberi layanan. Konseling berkaitan dengan upaya mempengaruhi perubahan tingkah laku secara sadar oleh klien. Dalam proses konseling, seorang konselor dapat menggunakan beberapa media sebagai alat bantu untuk menyampaikan informasi kesehatan dan mempermudah penerimaan pesan kesehatan bagi klien (Muzakar et al. 2018).

Gout merupakan penyakit yang berhubungan dengan tingginya kadar asam urat dalam darah. Penyakit ini disebabkan karena aktivitas fisik secara berlebihan yang mengakibatkan ekskresi asam urat melalui urin mengalami penurunan seperti kegiatan bertani, selain itu juga akibat tidak mengatur pola makan dengan baik sehingga asupan makanan yang mengandung purin menjadi berlebihan. Dampak yang timbul dari tingginya kadar asam urat yaitu timbulnya rasa nyeri pada daerah persendian sehingga dapat mengganggu aktivitas pekerjaan yang akan dilakukan (Prastyawati et al. 2021).

Asam urat merupakan hasil metabolisme akhir dari purin yaitu salah satu komponen asam nukleat yang terdapat dalam inti sel tubuh. Meningkatnya kadar asam urat dalam darah disebut dengan hiperurisemia. Hiperurisemia disebabkan oleh dua hal, yaitu karena pembentukan asam urat yang berlebihan atau karena penurunan pengeluaran asam urat oleh ginjal. Hiperurisemia yang tidak ditangani menyebabkan asam urat dalam darah berlebihan sehingga menimbulkan penumpukan kristal asam 
urat (Putrianti et al. 2019).

\section{DESAIN PENELITIAN}

Kegiatan penyuluhan dilaksanakan pada hari Sabtu, tanggal 13 Maret 2021 kantor Kelurahan Bercak, Wonosamudro, Boyolali. Sasaran dalam kegiatan ini adalah warga di Kelurahan Bercak. Metode yang digunakan dalam kegiatan ini adalah pemeriksaan kadar asam urat dilanjutkan dengan pemberian konseling. Media yang digunakan yaitu berupa leaflet tentang penyakit asam urat, kemudian dilanjutkan dengan Tanya jawab. Materi konseling yang diberikan mencakup Pengertian Asam Urat, Faktor Penyebab, Tanda dan gejala, Akibat Penyakit, Upaya Pencegahan, Penatalaksanaan, Pengobatan Secara Tradisional.

Pemeriksaan kadar asam urat dilakukan satu persatu kepada pasien. Evaluasi dilaksanakan dengan tujuan untuk menilai keberhasilan kegiatan ini, yakni dengan melihat antusias masyarakat melalui pertanyaan-pertanyaan yang diajukan ketika proses konseling serta pemahaman masyarakat yang diketahui melalui tanya jawab bersama konselor.

\section{HASIL PENELITIAN}

Hasil yang sudah dicapai dalam pengabdian ini adalah seluruh masyarakat yang hadir telah dilakukan pemeriksaan dan konseling dengan menerapkan protocol kesehatan secara ketat. Hasil yang dicapai setelah dilakukan pemeriksaan kadar asam urat yaitu warga menjadi lebih paham dalam menjaga kesehatan dan mengerti apa yang harus dilakukan jika terjangkit pengakit asam urat atau gout. Hasil evaluasi ketercapaian tahap persiapan kegiatan dapat dilihat dalam table berikut.

Tabel 1. Hasil Evaluasi Ketercapaian Tahap Persiapan Kegiatan

\begin{tabular}{lcc}
\hline \multicolumn{1}{c}{ Kegiatan } & \multicolumn{2}{c}{ Ketercapaian 100\% } \\
\cline { 2 - 3 } & Terlaksana & $\begin{array}{c}\text { Belum } \\
\text { terlaksana }\end{array}$ \\
\hline $\begin{array}{l}\text { Survei tempat pelaksanaan kegiatan } \\
\text { Pengurusan administrasi dan ijin lokasi pengabdian } \\
\text { masyarakat }\end{array}$ & $100 \%$ & - \\
$\begin{array}{l}\text { Persiapan alat dan bahan pelaksanaan kegiatan serta } \\
\text { materi leaflet }\end{array}$ & $100 \%$ & - \\
Ketercapaian tahap persiapan kegiatan & $100 \%$ & - \\
\hline
\end{tabular}

\section{PEMBAHASAN}

Dalam pelaksanaan kegiatan ini mendapat respon yang baik dari pihak Kelurahan Bercak dan seluruh masyarakat yang hadir. Seluruh kegiatan pengabdian masyarakat yang direncanakan dapat terlaksana $100 \%$ dalam kegiatan ini. Tahap pelaksanaan kegiatan pengabdian masyarakat tentang pemeriksaan kadar asam urat dan konseling pada masyarakat di Kelurahan Bercak, Wonosamudro, Boyolali antara lain:

1. Persiapan Tim

Sesampainya di lokasi, tim melaksanakan koordinasi dengan pihak kelurahan.

2. Proses Pemeriksaan Kesehatan

Kegiatan dilaksanakan pada pukul 15.00-Selesai, dengan diawali registrasi serta pengkajian awal dilanjutkan dengan pemeriksaan kadar asam urat. Hasil pemeriksaan 
dicatat dalam selembar kertas yang diberikan kepada warga disertai dengan penjelasan mengenai kadar asam urat yang normal.

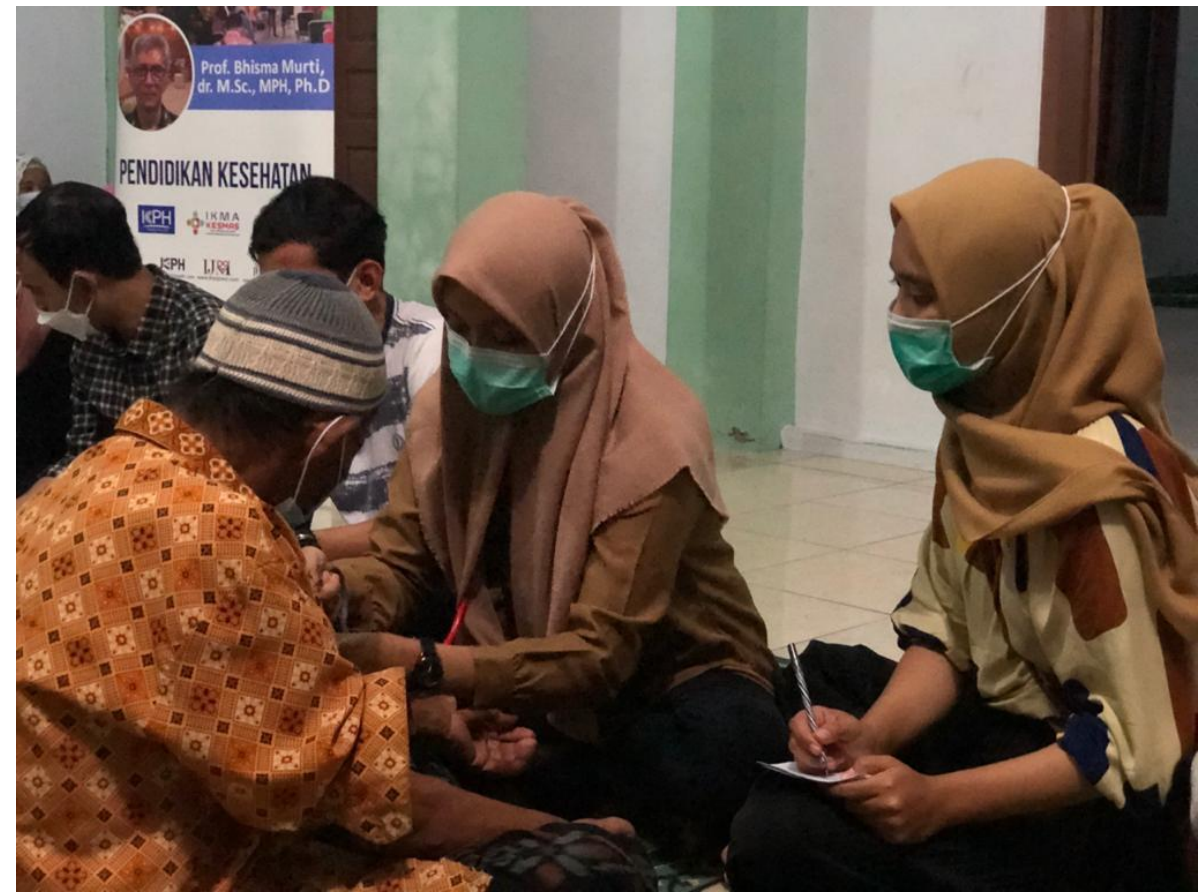

Gambar 1. Proses Pengkajian Awal

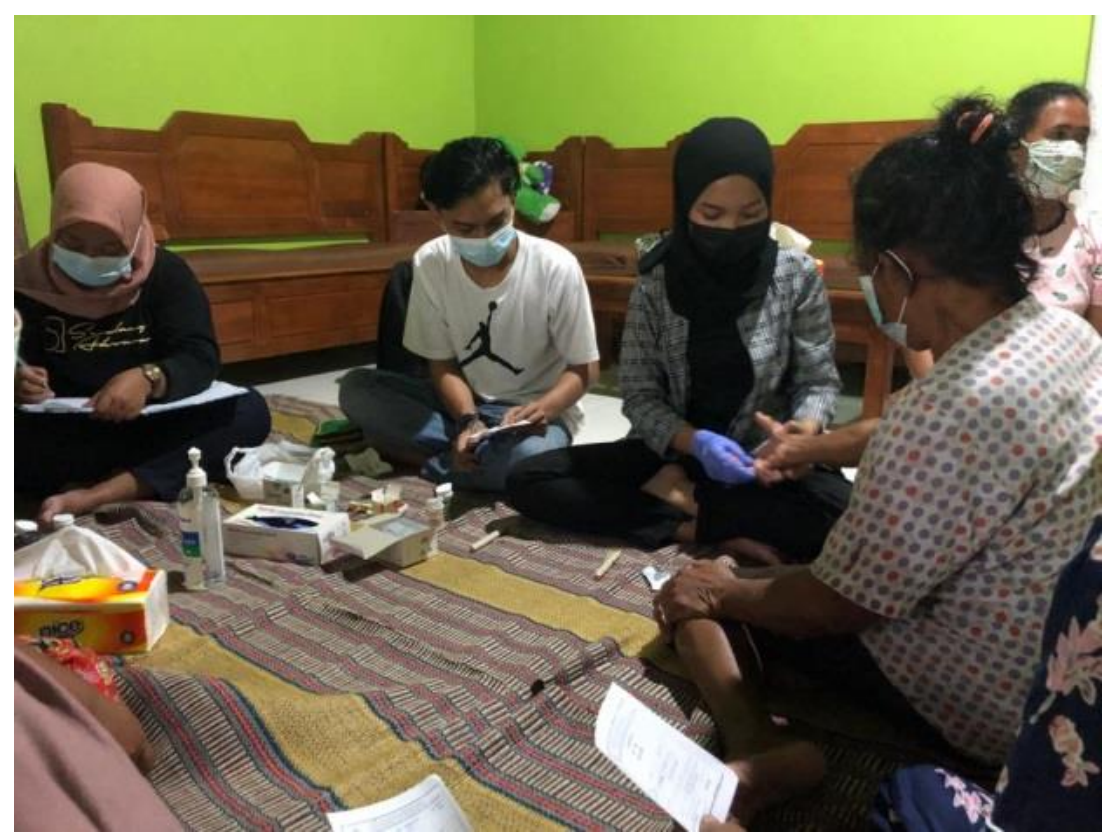

Gambar 2. Proses Pemeriksaan Asam Urat

\section{Proses Konseling}

Setelah dilakukan pemeriksaan pada warga, selanjutnya adalah pemberian konseling mengenai hasil pemeriksaan kadar asam urat. Konseling yang diberikan antara lain mengenai pengertian asam urat, faktor penyebab, tanda dan gejala, akibat penyakit, upaya pencegahan, penatalaksanaan, serta pengobatan secara tradisional. 


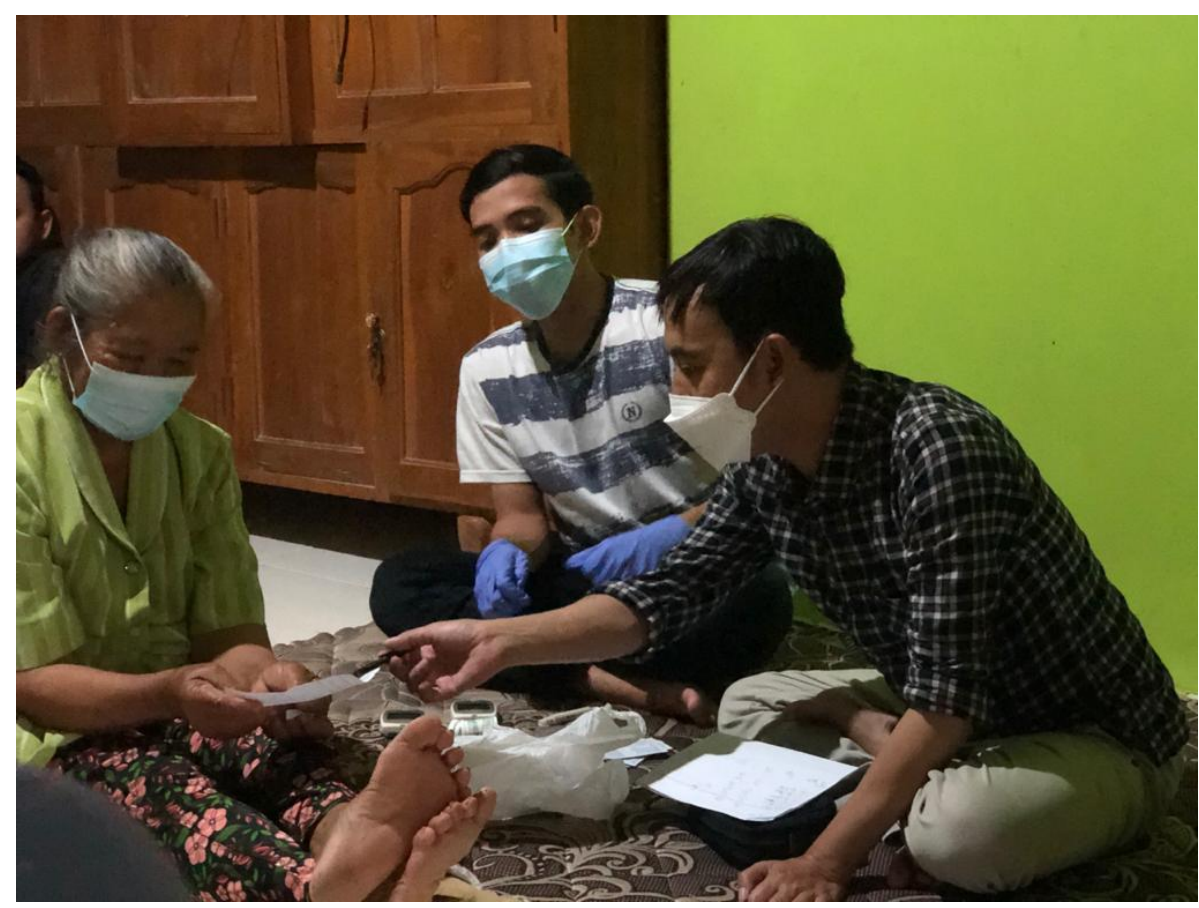

Gambar 3. Proses Konseling

Pelaksanaan kegiatan pengabdian masyarakat dapat berjalan dengan baik dan lancar. Melalui kegiatan tersebut, didapatkan bahwa setelah dilakukan konseling, kesadaran masyarakat untuk melakukan pemeriksaan kesehatan secara rutin meningkat. Tim melakukan koordinasi dengan pihak kelurahan untuk secara berkesinambungan melaksanakan pemantauan terhadap warga untuk melakukan tindak lanjut terhadap hasil pemeriksaan yang telah didapatkan oleh warga melalui kegiatan pengabdian masyarakat ini.

\section{KESIMPULAN DAN SARAN}

Kegiatan pengabdian yang telah dilaksanakan berupa pemeriksaan kadar asam urat dan pemberian konseling dapat terselenggara dengan baik dan lancar dilihat dari banyaknya masyarakat yang berpartisipasi serta antusias masyarakat selama mengikuti kegiatan. Diharapkan melalui kegiatan pengabdian yang dilaksanakan ini dapat meningkatkan pemahaman mengenai penyakit asam urat serta kesadaran masyarakat untuk rutin melakukan pemeriksaan kesehatan dan menghindari perilaku yang dapat berisiko buruk bagi kesehatannya.

Saran dari pelaksanaan kegiatan pengabdian masyarakat ini adalah setelah mitra memperoleh konseling dan mengetahui kadar asam uratnya, dapat ditindaklanjuti dengan melakukan pengobatan di puskesmas terdekat. (Mahendra and Arum 2021)

\section{UCAPAN TERIMAKASIH}

Penulis mengucapkan terimakasih kepada Prof. Bhisma Murti, dr, MPH, MSc, $\mathrm{PhD}$, selaku Ketua Program Studi Magister Ilmu Kesehatan Masyarakat Universitas Sebelas Maret, Ikatan Keluarga Mahasiswa dan Alumni (IKMA) KESMAS UNS, Sekolah Tinggi Ilmu Kesehatan Mamba'ul 'Ulum Surakarta, yang telah memfasilitasi kegiatan program kemitraan masyarakat ini. Penulis juga mengucapkan terimakasih kepada Pimpinan Kelurahan Bercak, Wonosamudro, Boyolali beserta perangkat kelurahan dan warga setempat atas dukungannya dalam kegiatan ini. 


\section{DAFTAR PUSTAKA}

(JAK), MT Sari-Jurnal Abdimas Kesehatan, and undefined 2019. n.d. "UPAYA PENINGKATAN PENGETAHUAN TENTANG ASAM URAT PADA LANSIA DI POSYANDU LANSIA RT 12 KELURAHAN RAWASARI." Jak.Stikba.Ac.Id.

Aprillia, F., D. Rahmawatie, and ED Noorratri. 2019. "PENERAPAN PEMBERIAN AIR REBUSAN DAUN SALAM TERHADAP KADAR ASAM URAT PADA PENDERITA ASAM URAT DI DESA MANDAN KECAMATAN."

Barsoum, Rashad, and Mohammed El-Khatib. 2017. "Uric Acid and Life on Earth." Journal of Advanced Research 8(5):471-74. doi: 10.1016/j.jare.2017.06.001.

Care, R. Afnuhazi-Jurnal Human, and undefined 2019. 2019. "Faktor-Faktor Yang Berhubungan Dengan Kejadian Gout Pada Lansia." Scholar.Archive.Org 4:34-41.

Fitriani, R., LM Azzahri, M. NURMAN-Jurnal Ners, and undefined 2021. n.d. "HUBUNGAN POLA MAKAN DENGAN KADAR ASAM URAT (GOUT ARTRITIS) PADA USIA DEWASA 35-49 TAHUN." Journal.Universitaspahlawan.Ac.Id.

Harrold, Leslie R., Kathleen M. Mazor, Daniel Peterson, Nausheen Naz, Cassandra Firneno, and Robert A. Yood. 2012. "Patients Knowledge and Beliefs Concerning Gout and Its Treatment: A Population Based Study." BMC Musculoskeletal Disorders 13(1):1. doi: 10.1186/1471-2474-13-180.

Mahendra, Himeldah Isa, and Puspito Arum. 2021. "Pengaruh Pemberian Sari Buah Kersen Terhadap Kadar Asam Urat Pada Penderita Hiperurisemia.” 10(1):1-13.

Muhaimin, AS, AD Nurlestari, AFD Nasihah, and G. Firdaus. n.d. "PENGABDIAN MASYARAKAT: PEMERIKSAAN KESEHATAN GRATIS PADA ERA PANDEMI COVID-19 DI TENGAH TANI, CIREBON.” Kkn.Unnes.Ac.Id.

Muzakar, M., T. Terati, M. Mulizha- Publikasi, and Undefined 2018. 2018. "PENGARUH KONSELING DIET RENDAH PURIN DAN TINGGI OMEGA-3 TERHADAP KADAR ASAM URAT PASIEN GOUT RAWAT JALAN DI RUMAH SAKIT Dr. AK.” Pkp.Balitbangnovdasumsel.Com.

Ndede, VZLP, W. Oroh, H. Bidjuni-Jurnal Keperawatan, and undefined 2019. n.d. "PENGARUH PEMBERIAN REBUSAN DAUN SALAM TERHADAP PENURUNAN KADAR ASAM URAT PADA PENDERITA GOUT ARTRITIS DI WILAYAH.” Ejournal.Unsrat.Ac.Id.

Pasalic, Daria, Natalija Marinkovic, and Lana Feher-Turkovic. 2012. "Uric Acid as One of the Important Factors in Multifactorial Disorders - Facts and Controversies." Biochemia Medica 22(1):63-75. doi: 10.11613/bm.2012.007. 
Prastyawati, Rini, Ester Rampa, Tika Romadhonni, Program Studi, Analis Kesehatan, and Kata Kunci. 2021. "SOSILASISASI PENCEGAHAN PENYAKIT GOUT DAN PEMERIKSAAN ASAM URAT PADA PETANI KAMPUNG SEAFEN EMPAT DUA DISTRIK SKANTO.” Ojs.Ustj.Ac.Id 2(2):6-11.

Putrianti, Berlina, Amri Wulandari, Program Studi DIII Kebidanan, and Akademi Kesehatan Karya Husada Yogyakarta. 2019. "PENINGKATAN PENGETAHUAN DAN SCREENING PENYAKIT GOUT DENGAN PEMERIKSAAN ASAM URAT PADA LANSIA DI DESA MAJASEM YOGYAKARTA.” Jurnal.Poltekkeskhjogja.Ac.Id 1(1).

Rosdiana, DS, A. Khomsan-Media Pendidikan, undefined Gizi, and undefined 2018. 2018. "Pengetahuan Asam Urat, Asupan Purin Dan Status Gizi Terhadap Kejadian Hiperurisemia Pada Masyarakat Perdesaan.” Ejournal.Upi.Edu 7(2).

Sani, FN, ACN Afni-Dinamika Kesehatan: Jurnal, and undefined 2019. n.d. "Pengaruh Pemberian Jus Sirsak (Annona Muricata Linn) Terhadap Kadar Asam Urat Pada Lansia Dengan Gout.” Ojs.Dinamikakesehatan.Unism.Ac.Id.

Syarifuddin, LA, AM Taiyeb, MW Caronge-Seminar Nasional Biologi, and undefined 2019. n.d. "Hubungan Pola Makan Dan Aktivitas Fisik Dengan Kadar Asam Urat Dalam Darah Pada Penderita Asam Urat (Gout) Di Wilayah Kerja Puskesmas Sabbangparu." Ojs.Unm.Ac.Id.

Widiyanto, Aris, Krisnanda Aditya Pradana, Faisal Hidayatullah, Joko Tri Atmojo, Ndaru Syukma Putra, and Asruria Sani Fajriah. 2020. "Efektifitas Kompres Hangat Daun Kelor Terhadap Nyeri Asam Urat Pada Lansia Di Desa Kenteng,Nogosari, Boyolali." Avicenna : Journal of Health Research 3(2):10313. doi: 10.36419/avicenna.v3i2.422.

Yunita, Ema P., Dinar I. Fitriana, and Atma Gunawan. 2018. "Associations between Obesity, High Purine Consumptions, and Medications on Uric Acid Level with the Use of Allopurinol in Hyperuricemia Patients." Indonesian Journal of Clinical Pharmacy 7(1):1-9. doi: 10.15416/ijcp.2018.7.1.1. 